\title{
Energy consumption analysis of battery electric vehicles in underground environments
}

\author{
S Kukkonen Normet Oy, Finland
}

\begin{abstract}
Battery electric vehicles (BEVs) have many benefits over conventional diesel powered vehicles such as higher energy efficiency, no local emissions, reduced need for ventilation, lower operating costs, less maintenance need and higher performance. On the other hand, BEVs have a shorter operating range than diesel vehicles. In order to realise all benefits, mining operation and design need to be adapted to the requirements of BEVs. One approach is to carry out energy consumption analysis of different vehicles and to optimise mining processes using such information. In this paper, the BEV energy consumption of driving and processes are analysed. Processes such as explosives charging, concrete spraying and logistics are discussed. The resulting energy consumption information is then used to discuss any adaptation requirements to operational mining and design. This includes topics like how to design battery charging infrastructure for uninterrupted operation and prospects of battery operated processes and operational expense savings.
\end{abstract}

Keywords: battery electric vehicles, fully electric, batteries, energy consumption

\section{Introduction}

Diesel fuel has a volumetric energy density of approximately $10 \mathrm{kWh}$ per litre. It can be easily transported and refilled into a tank in a matter of minutes. On the other hand, modern automotive lithium-ion (Li-ion) batteries have an energy density of around $500 \mathrm{Wh}$ per litre - only a fraction of that of a diesel fuel (Kukkonen 2014). From this comparison, along with being the incumbent technology, it is easy to understand why diesel powered vehicles dominate underground mining. The energy density enabling long operating time and ease of refuelling are key benefits of diesel vehicles. However, diesel emissions have adverse health effects in closed spaces due to emissions which have to be removed with mine ventilation (Peters et al. 2016; Silverman et al. 2012). Also, diesel vehicles have high operating costs due to the price of diesel fuel and high ventilation requirements. Battery operated vehicles, however, have no local emissions, generate less heat and noise, and are highly efficient in terms of using energy. Ventilation and mine cooling can be reduced when utilising battery powered electric mining vehicles, enabling significant operating cost savings (Landry 2016; Jacobs et al. 2014; Paraszczak et al. 2013). In order to realise all of these benefits, mining operations need to adapt to the inherent limitations of battery powered electric vehicles. The limitations include shorter range and longer refilling (charging) time of batteries when compared to equivalent diesel powered vehicles. This paper presents energy consumption analysis of battery operated underground mining vehicles. The approach can be subsequently used to design a reliable and uninterrupted mining operation. This paper concentrates on energy consumption analysis of so-called ancillary equipment such as charging, spraying, and logistics machines due to the author's experience with them. However, the approach presented in this paper can be used for any type of machine.

\section{Battery electric vehicle fundamentals}

In BEVs, conventional diesel powered drivelines are replaced with battery powered ones. Many different battery electric driveline architectures exist but, fundamentally, the diesel engine, gearbox, shafts and fuel tank are replaced with a battery, motor drives, electric motors, and possibly gearboxes and shafts. The driveline architecture and design defines the efficiency and performance of a BEV. A high-efficiency driveline consumes less $\mathrm{kWh}$ per kilometre in uphill driving and can recover more $\mathrm{kWh}$ per kilometre in 
downhill driving than a low-efficiency driveline (Halmeaho 2016). The battery of a BEV defines how much energy is available for use (operating range or time) and how fast the energy can be discharged or charged. This determines the power rating of the vehicle together with the driveline architecture but also sets the limitation on the fastest possible charging time. The charging time is defined by the capability of the battery and the power rating of the charging system.

\subsection{Industrial lithium-ion batteries as an enabling technology}

Modern electric vehicles utilise Li-ion batteries. Li-ion battery is an umbrella term consisting of many different materials and chemistries that can be used to realise a Li-ion battery. In the end, it is the material selection that determines the characteristics of a Li-ion battery. Some material combinations have better energy density, some better safety, lifespan or charging capability. A battery is always a compromise between different performance characteristics. It is not possible to have the highest energy density and fastest charging time at the same time. For underground mining applications, the most important battery characteristics include safety, high power, fast charging time and long lifespan. One of the few Li-ion chemistries having these characteristics is the lithium-titanate (LTO) battery. With LTO, it is possible to achieve a very long-lasting battery that can be charged in $15 \mathrm{~min}$. at the expense of physical size and weight. With a 15 min. charging time, uninterrupted mining operation is made possible (Kukkonen 2014; Battery University 2017).

\subsection{Fast charging systems as an enabling technology}

Li-ion LTO is an enabling technology due to the capability for 15 min. charging times. Such a short charging time requires a very high-power charging system. For example, if the battery energy content is $100 \mathrm{kWh}$, a $15 \mathrm{~min}$. charging time requires a $400 \mathrm{~kW}$ charging system. Such a charging system is feasible but a few considerations must be made. Currently, there are different kinds of charging systems available. The main types are (i) on-board AC charging systems, and (ii) off-board DC charging systems (Global Mining Standards and Guidelines Group (GMSG) 2017). On-board charging systems are very easy to implement and use because common industrial AC plugs and sockets can be utilised. The disadvantage is that the actual charging system is installed on-board the vehicle. Volume and cost limitations typically limit the maximum power rating of an on-board charging system to a few tens of kilowatts. On the other hand, off-board DC charging systems are installed off-board the vehicle and can be considered part of the infrastructure supporting the vehicles. With these systems, it is possible to achieve several hundred kilowatts of charging power enabling the $15 \mathrm{~min}$. charging time. Thanks to the electric car industry, there are universal standards available for DC charging. One such standard set is the combined charging standard (CCS). It includes much of the necessary functionality needed in mining and can be easily adapted for underground use. It also includes numerous safety mechanisms because it is being used in cars (GMSG 2017; The Charging Interface Initiative e.V. 2017).

\section{Energy consumption analysis methodology}

An underground mining vehicle consumes electrical energy not only during driving, but also during processes such as concrete spraying or explosives charging. Battery charging is conducted when on-board or off-board chargers are connected to the vehicle and during downhill driving. There are two practical methods for analysing the energy consumption of a vehicle: direct measurements or by developing a mathematical representation (model) of the vehicle (Rahkola 2016). The benefit of direct measurements is that they provide accurate energy consumption information. The downside is that a direct measurement only provides information on the driving condition of the vehicle during the measurement. For analysing multiple driving scenarios, modelling and simulations are typically used because of their versatility. For achieving versatility and accuracy, the developed models can be validated and calibrated with direct measurements. This method provides confidence that simulation results are accurate while requiring only a minimum amount of direct measurements. 


\subsection{Energy flow model}

In an underground BEV, battery energy is used for different purposes: (i) driving, (ii) auxiliary systems (such as cooling/heating and lights), and (iii) processes. During driving, energy is being consumed by (i) and (ii) and during process, (ii) and (iii). The energy consumption for auxiliary systems and processes are vehicle and process specific. Therefore, in this paper, the energy demand for these two terms is estimated or based on direct measurements. Driving energy consumption can be calculated and represented as mathematical equations much more easily. In this paper, a longitudinal dynamic vehicle model has been built that includes resistive forces such as rolling resistance and climbing force. Aerodynamic drag has been omitted because underground vehicles are driven slowly. This vehicle model is then incorporated into an energy flow model which includes efficiency maps of the components used inside a BEV. Subsequently, this energy flow model is used to simulate different driving scenarios for calculating the energy consumption of a vehicle. The model has been implemented as follows. First, the force needed to move the vehicle can be approximated from:

$$
F=m g(\sin (\alpha)+\mu \cos (\alpha))
$$

where:

$$
\begin{aligned}
& \mathrm{m} \quad=\text { the mass of the vehicle. } \\
& \mathrm{g} \quad=\text { the gravity. } \\
& \alpha \quad=\text { the slope. } \\
& \mu \quad=\text { the rolling resistance. }
\end{aligned}
$$

The power needed from the battery to move the vehicle forward at given speed can be calculated from Equation 2.

$$
P=\frac{v F}{\eta_{-} t o t}
$$

where:

$$
\begin{aligned}
& v \quad=\text { the speed of the vehicle. } \\
& F \quad=\text { the force needed to move the vehicle. } \\
& \eta_{\text {ntot }}=\text { the total efficiency of the vehicle. }
\end{aligned}
$$

The energy consumed from the battery can then be calculated from:

$$
E=\frac{P d}{v}
$$

where:

$$
\begin{aligned}
& \mathrm{P} \quad=\text { the power. } \\
& \mathrm{d} \quad=\text { the distance in } \mathrm{km} .
\end{aligned}
$$

When driving downhill, the energy flow is reversed and is flowing from road surface back to the battery, thus the following equations must be used:

$$
\begin{gathered}
F_{\text {downhill }}=m g(\sin (\alpha)-\mu \cos (\alpha)) \\
P_{\text {downhill }}=v F \eta_{-} \text {tot } \\
E=\frac{P d}{v}
\end{gathered}
$$


The vehicle dynamics are easily represented mathematically. A crucial variable in these calculations is the total efficiency of the vehicle $\eta_{-}$tot. This term is not constant, because different components such as motors, batteries, inverters, axles, etc. have efficiencies that are dependent on the operating point of the component. As an example, motor efficiency is heavily dependent on voltage, rotational speed, and torque, whereas axle efficiency is dependent on rotational speed and oil temperature.

To implement an accurate energy flow model, efficiency maps of various components are incorporated to calculate the $\eta_{-}$tot in the different operating points at which the vehicle is being used. The energy flows of the vehicle are described in Figure 1.

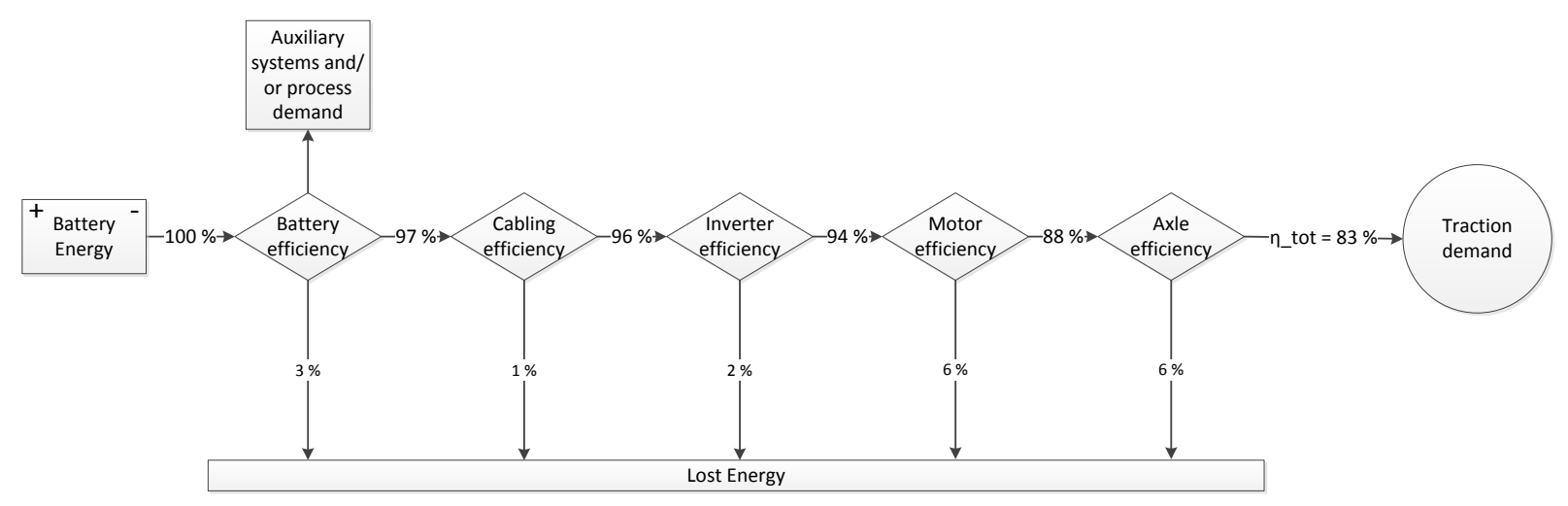

Figure 1 Energy flow model

As can be determined from Figure 1, the energy flow model includes a battery efficiency map, cabling efficiency, inverter efficiency map, motor efficiency map and axle efficiency maps. These contribute to the total efficiency of the vehicle $\eta_{-}$tot before any resistive forces. $\eta_{-}$tot varies according to speed, loading and other factors but, as described in Figure 1, it can be over $80 \%$ if the driveline has been designed properly. Furthermore, auxiliary systems and/or process energy demand has been included in the figure and are based on estimation or direct measurements. In this paper, auxiliary system demand has been approximated to be $10 \mathrm{~kW}$ at all times and includes systems such as hydraulics used during driving, air conditioning, cabin heating, lights, etc. Process energy consumption is discussed in the subsequent section.

\subsection{Process energy consumption}

In underground mining, there are numerous different processes conducted with purposely built vehicles. Due to the complexity of the processes and the hardware used, it is feasible to rely on direct measurements and/or approximation of the process power consumption. In this paper, direct measurements of emulsion charging power consumption are presented. The total emulsion power consumption is described in Figure 2. 


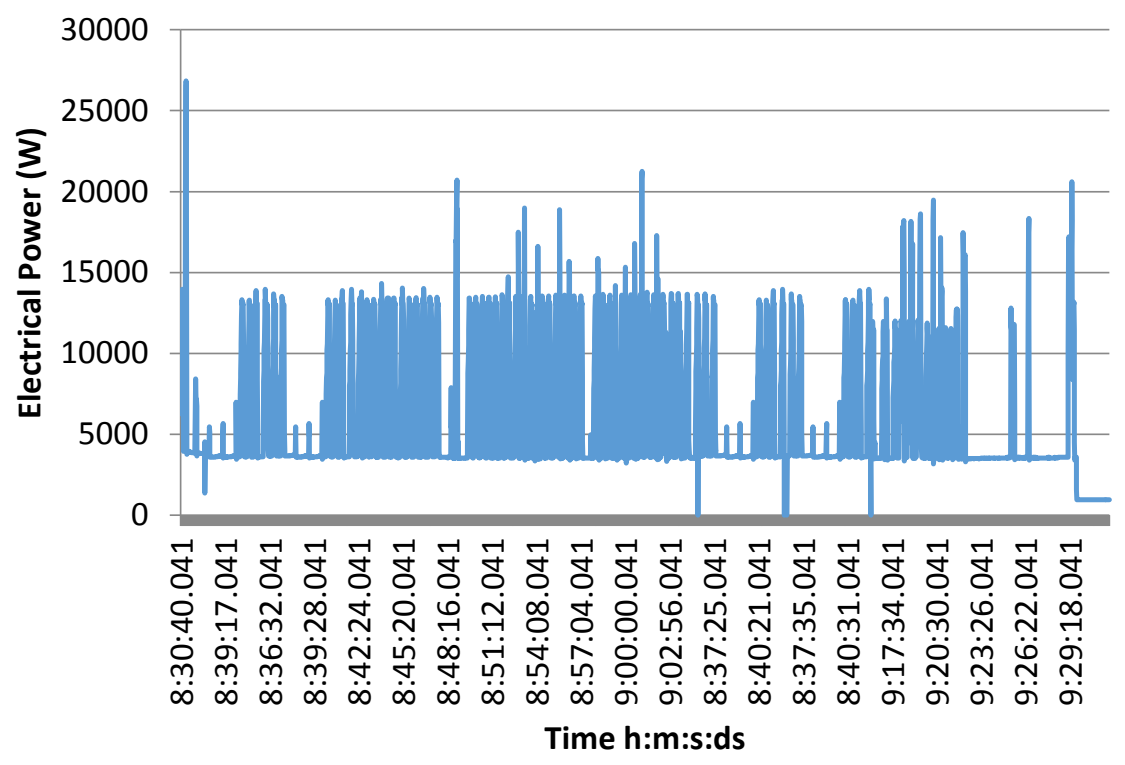

Figure 2 Emulsion charging process energy consumption

The measurements described in Figure 2 were conducted in a Finnish mine in early 2017. During this one hour measurement period, the face was loaded with emulsion explosives. The average power consumption during this time period was only $6.2 \mathrm{~kW}$. Typical power transients were approximately $13 \mathrm{~kW}$ of power caused by boom movement and emulsion pump utilisation. The average power consumption of $6.2 \mathrm{~kW}$ is used in the energy consumption simulations in the subsequent section.

Other processes discussed in subsequent sections include concrete transport and concrete spraying. No measurement data is currently available from these two processes. Estimated power demand in a concrete transport vehicle is $15 \mathrm{~kW}$ on average for the container rotation. The concrete spraying power level is estimated to be $25 \mathrm{~kW}$ on average with external air supply. If external air supply is not available and on-board compressor is used, the power consumption for the spraying process will be around $100 \mathrm{~kW}$.

\section{$4 \quad$ Simulations and results}

In this section, the energy flow model is used to simulate three different proposed work cycles: (i) logistics cycle, (ii) charging cycle, and (iii) spraying cycle. Energy consumption tables are provided which will allow the reader to make their own energy consumption analyses.

\subsection{Logistics cycle}

Here a concrete transport logistics cycle is described and simulated. The following assumptions are used: $90 \mathrm{kWh}$ battery, auxiliary systems consumption of $10 \mathrm{~kW}$, process consumption of $15 \mathrm{~kW}$, and rolling resistance of $3 \%$. Unloaded machine weight is $15,000 \mathrm{~kg}$ and fully loaded is $30,000 \mathrm{~kg}$. The battery has been charged to $50 \%$ of capacity at the beginning of the cycle. The logistics cycle used is as follows:

- The machine is filled with concrete in $30 \mathrm{~min}$. The battery is being charged with a $50 \mathrm{~kW}$ off-board charging system.

- Machine trams 1,000 m fully loaded on level surface at $12 \mathrm{~km} / \mathrm{h}$.

- Machine trams 2,000 m downhill fully loaded on $-15 \%$ slope at $12 \mathrm{~km} / \mathrm{h}$.

- Machine trams 1,000 m on level surface fully loaded at $12 \mathrm{~km} / \mathrm{h}$.

- Machine is unloaded in $30 \mathrm{~min}$. and is charged with a $30 \mathrm{~kW}$ on-board charging system. 
- Machine trams $1,000 \mathrm{~m}$ on level surface empty at $15 \mathrm{~km} / \mathrm{h}$.

- Machine trams $2,000 \mathrm{~m}$ uphill empty on $15 \%$ slope at $12 \mathrm{~km} / \mathrm{h}$.

- Machine trams 1,000 m empty on level surface back to the batching plant for next round at $15 \mathrm{~km} / \mathrm{h}$.

- Repeat once.

In Figure 3, the results of the simulation of two consecutive logistics cycles are presented. The uppermost graph describes stored battery energy in kWh, the second is battery power in kW and the third is the distance trammed in kilometres.
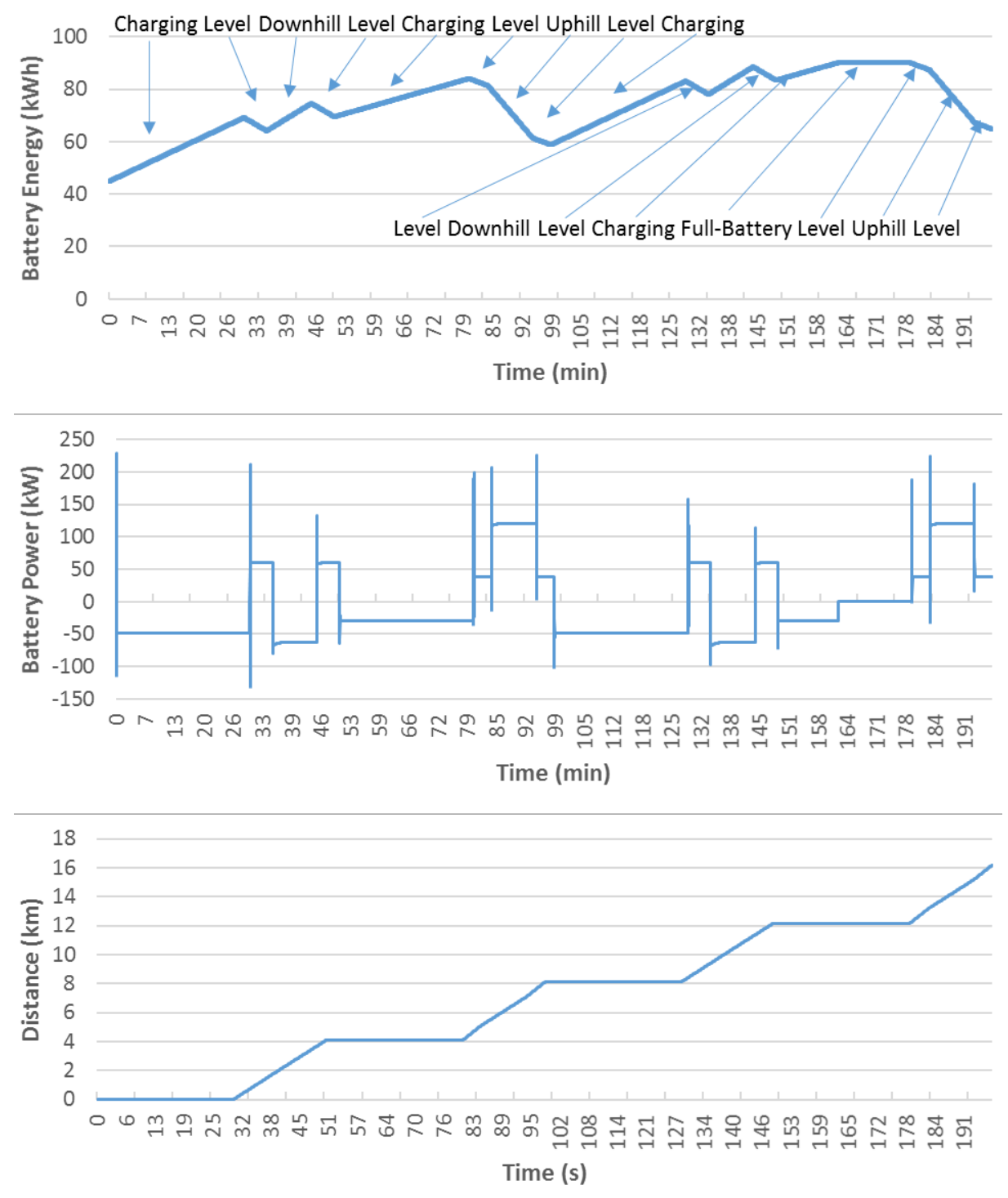

Figure 3 Logistics cycle simulation results

As can be determined from Figure 3, the majority of the energy is being used during uphill driving in the middle of the cycle. However, braking energy regeneration and battery charging at the batching plant and worksite are enough to provide more energy to the vehicle than it actually needs. At the beginning of the cycle, $45 \mathrm{kWh}$ of energy was stored inside the battery, and at the end of two cycles, over $60 \mathrm{kWh}$. This means that this cycle can be run continuously. If battery charging at the worksite or batching plant is difficult to accomplish, alternative charging locations can also be considered. One good alternative would be to install a more powerful charging station, such as a $100 \mathrm{~kW}$ off-board charging station, near the batching plant. Such an arrangement is simulated in the next subsection. 


\subsubsection{Logistics cycle with fast-charging}

Here, the same logistics cycle as the previous one is simulated with the difference being that charging is conducted only at the batching plant. The charger is an off-board charger with a $100 \mathrm{~kW}$ power output.

As can be determined from Figure 4, fast-charging at a batching plant is a good alternative. All of the energy needed for tramming is provided during concrete fill by the $100 \mathrm{~kW}$ off-board fast-charging station. Unloading is conducted battery powered and does not require any external power source.
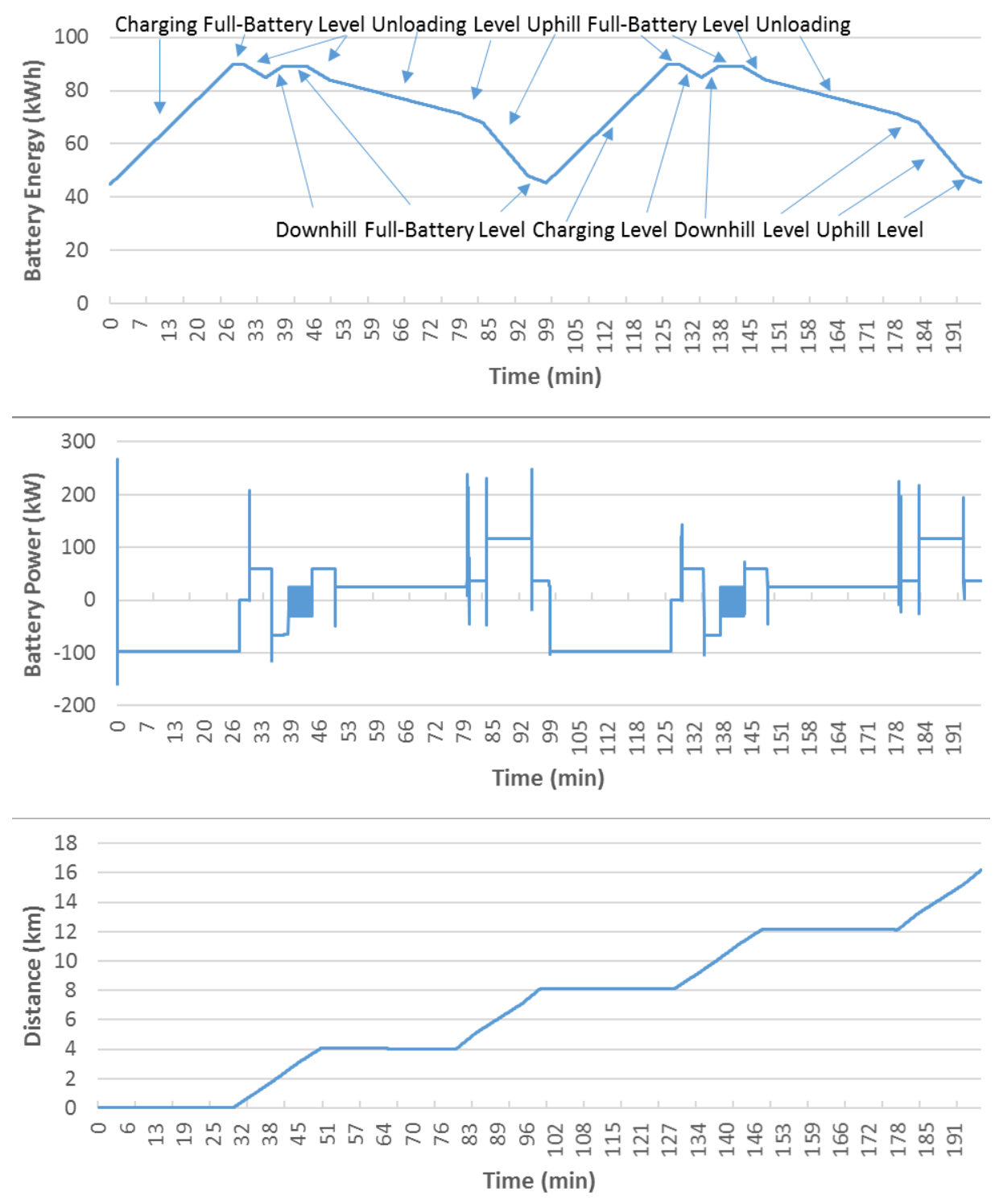

Figure 4 Logistics cycle with fast-charging simulation results

\subsection{Emulsion charging cycle}

Here an emulsion charging cycle is described and simulated. The following assumptions are used: $90 \mathrm{kWh}$ battery, auxiliary systems consumption of $10 \mathrm{~kW}$, process consumption of $6.2 \mathrm{~kW}$ and rolling resistance of $3 \%$. Machine weight is $25,000 \mathrm{~kg}$. The battery has been charged to $50 \%$ of capacity at the beginning of the cycle. The following charging cycle is used:

- Machine trams $1,000 \mathrm{~m}$ on level surface at $12 \mathrm{~km} / \mathrm{h}$.

- Machine trams 2,000 m downhill on $-15 \%$ slope at $12 \mathrm{~km} / \mathrm{h}$.

- Machine trams $1,000 \mathrm{~m}$ on level surface at $12 \mathrm{~km} / \mathrm{h}$. 
- Machine conducts charging process; grid is connected for $60 \mathrm{~min}$. and is charged with a $30 \mathrm{~kW}$ on-board charging system.

- Machine trams $1,000 \mathrm{~m}$ on level surface at $12 \mathrm{~km} / \mathrm{h}$.

- Machine trams $2,000 \mathrm{~m}$ uphill on $+15 \%$ slope at $12 \mathrm{~km} / \mathrm{h}$.

- Machine trams $1,000 \mathrm{~m}$ on level surface at $12 \mathrm{~km} / \mathrm{h}$.

- $15 \mathrm{~min}$. battery charging at $50 \mathrm{~kW}$ off-board charging station.

- Repeat once.

In Figure 5, the results of the simulation of two consecutive charging cycles are presented. The uppermost graph describes stored battery energy in $\mathrm{kWh}$, the second is battery power in $\mathrm{kW}$ and the third is the distance trammed in kilometres.
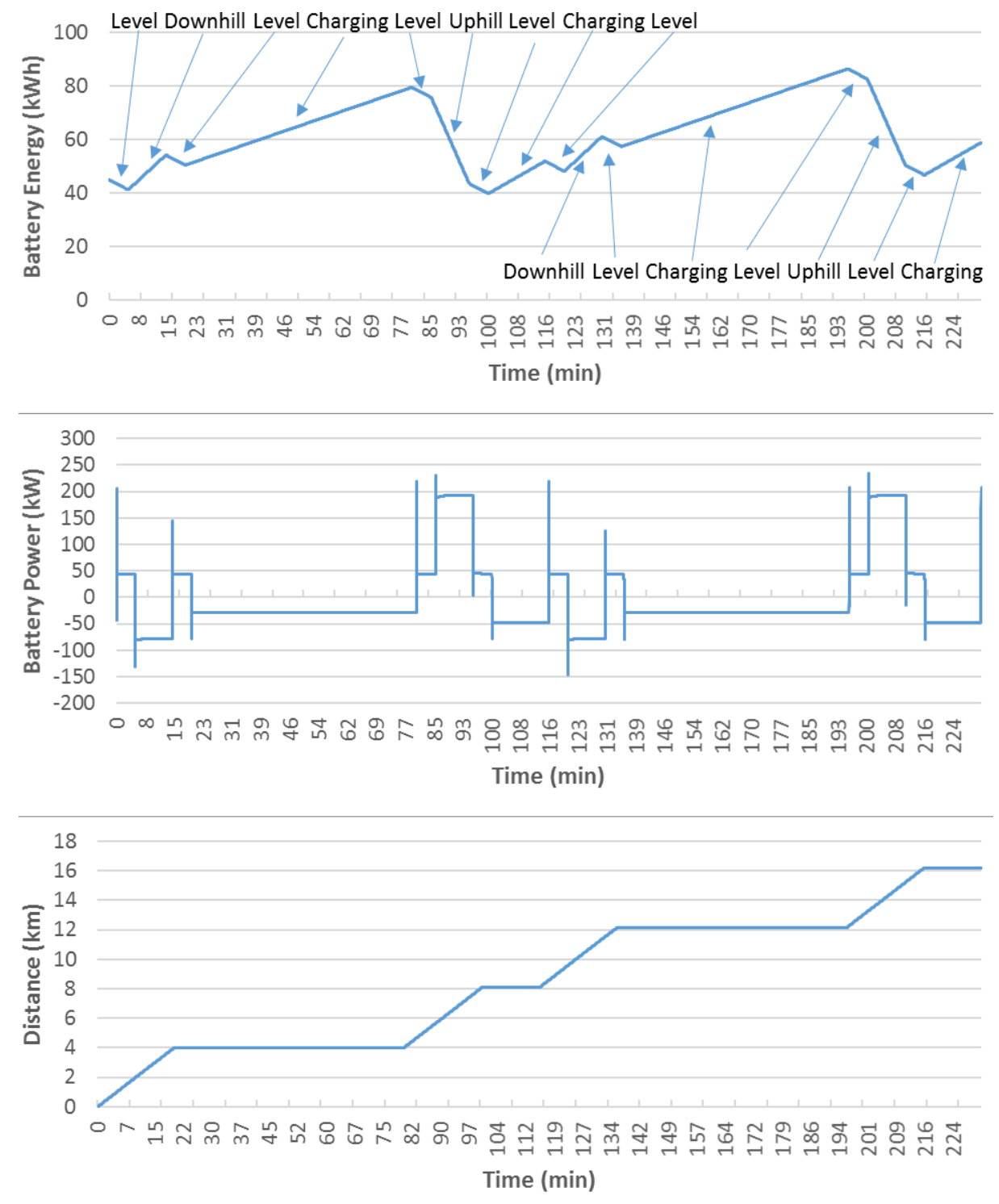

Figure 5 Charging cycle simulation results 
As can be derived from Figure 5, the majority of the energy is used during uphill driving, but there is enough energy charged at the worksite, fast-charging station and during downhill driving to replenish the used energy. At the beginning of the cycle, $45 \mathrm{kWh}$ of energy was stored inside the battery, and after two consecutive cycles, approximately $50 \mathrm{kWh}$. The cycle can be run continuously. Charging at the worksite and additional $15 \mathrm{~min}$. $50 \mathrm{~kW}$ charging is enough to sustain the energy balance. Here, fast-charging can be considered in the same manner as with the logistics cycle.

\subsection{Spraying cycle}

Here a concrete spraying cycle is described and simulated. The following assumptions are used: $90 \mathrm{kWh}$ battery, auxiliary systems consumption of $10 \mathrm{~kW}$, process consumption of $100 \mathrm{~kW}$ (the mine does not have an external air supply) and rolling resistance of $3 \%$. Machine weight is $20,000 \mathrm{~kg}$. The battery has been charged to $50 \%$ of capacity at the beginning of the cycle. The spraying cycle used is as follows:

- Machine trams $1,000 \mathrm{~m}$ on level surface.

- Machine trams 2,000 m downhill on $-15 \%$ slope.

- Machine trams $1,000 \mathrm{~m}$ on level surface.

- Machine conducts spraying process; grid is connected for $45 \mathrm{~min}$. and is charged with a $30 \mathrm{~kW}$ on-board charging system.

- Machine trams 1,000 m on level surface.

- Machine trams $500 \mathrm{~m}$ uphill on $15 \%$ slope.

- Machine trams 1,000 m on level surface.

- Machine conducts spraying process; grid is connected for $45 \mathrm{~min}$. and is charged with a $30 \mathrm{~kW}$ on-board charging system.

- Machine trams $1,000 \mathrm{~m}$ on level surface.

- Machine trams $500 \mathrm{~m}$ uphill on $15 \%$ slope.

- Machine trams $1,000 \mathrm{~m}$ on level surface.

- Machine conducts spraying process; grid is connected for $45 \mathrm{~min}$. and is charged with a $30 \mathrm{~kW}$ on-board charging system.

In Figure 6, the results of the simulation are presented. The uppermost graph describes stored battery energy in $\mathrm{kWh}$, the second is battery power in $\mathrm{kW}$, and the third is the distance trammed in kilometres. 

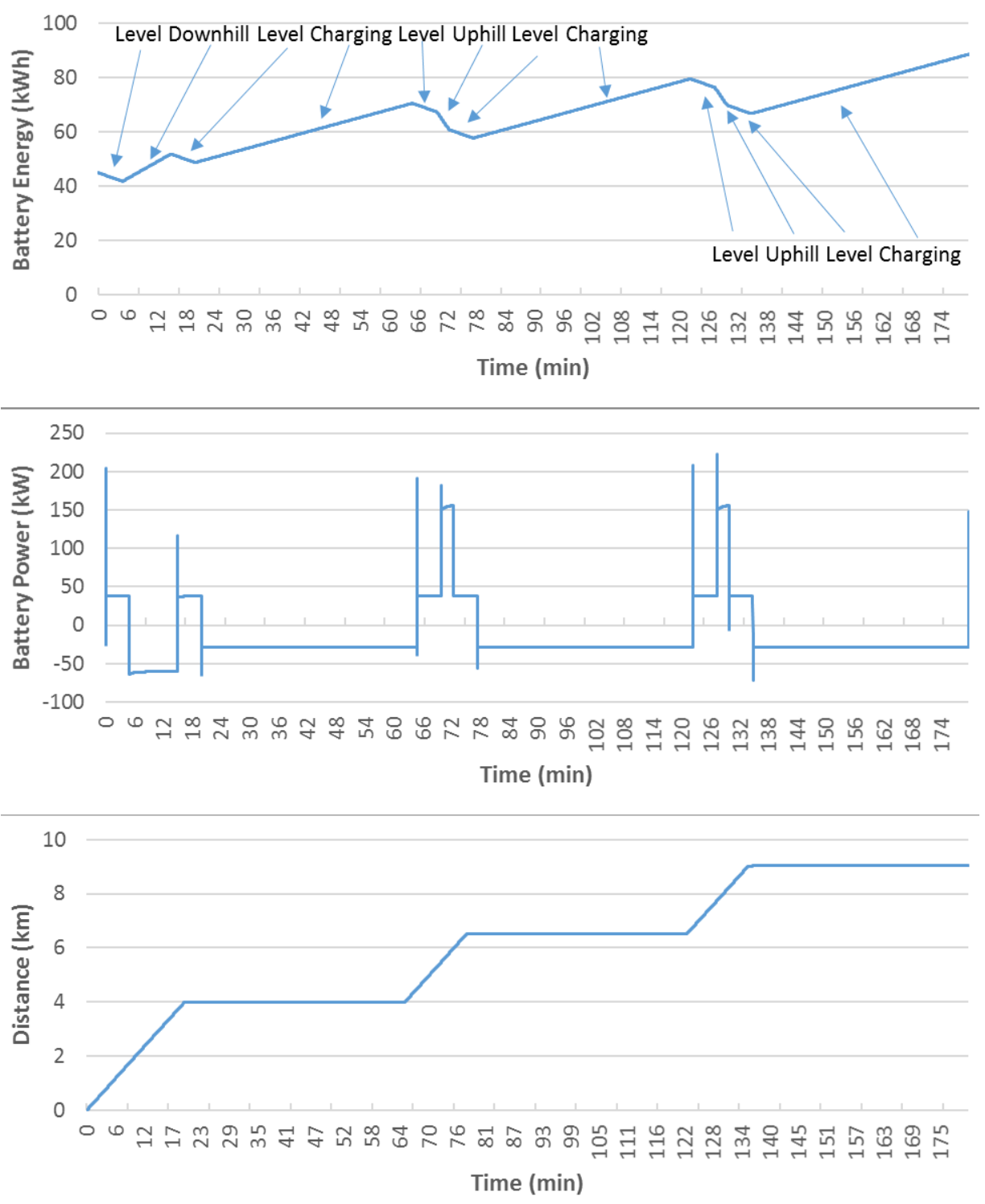

Figure 6 Spraying cycle simulation results

As can be determined from Figure 6, it is feasible to spray one face and then continue to the next worksite. Enough energy is being charged during spraying to enable continuous working life without adding additional charging periods. There is considerably more energy stored inside the battery after the cycle than at the beginning of the cycle.

\subsection{Energy consumption tables}

In addition to simulating work cycles with the energy flow model, the model can be used to create energy consumption tables that can be subsequently used to manually estimate energy consumption of driving. In Table 1, energy consumption of level driving and on various inclines is described as energy used per kilometre $(\mathrm{kWh} / \mathrm{km})$. Table 2 is similar, but describes how much energy can be regenerated per kilometre of downhill driving. In all cases, the vehicle speed is $10 \mathrm{~km} / \mathrm{h}$, auxiliary power consumption is $10 \mathrm{~kW}$ and rolling resistance is $3 \%$. Efficiency $\eta$ tot is over $80 \%$. 
Table 1 Energy consumption during level and uphill driving

\begin{tabular}{lllll}
\hline Slope/vehicle weight & $\mathbf{1 5 ~ t}$ & $\mathbf{2 0 ~ t}$ & $\mathbf{2 5} \mathbf{3 0 ~ t}$ \\
\hline $0 \%$ & $3.13 \mathrm{kWh} / \mathrm{km}$ & $3.66 \mathrm{kWh} / \mathrm{km}$ & $4.34 \mathrm{kWh} / \mathrm{km}$ & $4.72 \mathrm{kWh} / \mathrm{km}$ \\
$5 \%$ & $5.62 \mathrm{kWh} / \mathrm{km}$ & $6.86 \mathrm{kWh} / \mathrm{km}$ & $8.15 \mathrm{kWh} / \mathrm{km}$ & $9.43 \mathrm{kWh} / \mathrm{km}$ \\
$10 \%$ & $7.96 \mathrm{kWh} / \mathrm{km}$ & $10.1 \mathrm{kWh} / \mathrm{km}$ & $12.2 \mathrm{kWh} / \mathrm{km}$ & $14.4 \mathrm{kWh} / \mathrm{km}$ \\
$15 \%$ & $10.4 \mathrm{kWh} / \mathrm{km}$ & $13.3 \mathrm{kWh} / \mathrm{km}$ & $16.5 \mathrm{kWh} / \mathrm{km}$ & $19.6 \mathrm{kWh} / \mathrm{km}$ \\
$20 \%$ & $12.8 \mathrm{kWh} / \mathrm{km}$ & $16.8 \mathrm{kWh} / \mathrm{km}$ & $20.8 \mathrm{kWh} / \mathrm{km}$ & $26.6 \mathrm{kWh} / \mathrm{km}$ \\
\hline
\end{tabular}

Table 2 Energy regeneration during downhill driving

\begin{tabular}{lllll}
\hline Slope/vehicle weight & $\mathbf{1 5 t}$ & $\mathbf{2 0 ~ t}$ & $\mathbf{2 5 t}$ & $\mathbf{3 0 t}$ \\
\hline$-15 \%$ & $-3.81 \mathrm{kWh} / \mathrm{km}$ & $-4.63 \mathrm{kWh} / \mathrm{km}$ & $-5.24 \mathrm{kWh} / \mathrm{km}$ & $-5.85 \mathrm{kWh} / \mathrm{km}$ \\
\hline
\end{tabular}

As can be determined from Tables 1 and 2, vehicle weight has a significant effect on how much energy the vehicle consumes. Heavy vehicles typically require powerful charging systems to support their energy demand as well. With these tables, carrying out manual energy consumption analyses is straightforward. For example, a $25 \mathrm{t}$ vehicle driving $2 \mathrm{~km}$ on a $15 \%$ slope consumes $2 \mathrm{~km} \times 16.5 \mathrm{kWh} / \mathrm{km}=33 \mathrm{kWh}$ of energy. On the other hand, $30 \mathrm{~min}$. of charging with $50 \mathrm{~kW}$ of power provides $0.5 \mathrm{~h} \times 50 \mathrm{~kW}=25 \mathrm{kWh}$ energy before any charging losses. This way, energy consumption of vehicles is easily estimated by hand.

\section{Discussion and conclusion}

With the energy flow model that includes dynamic vehicle model and efficiency maps of the components, it is easy to carry out accurate energy consumption analyses for different vehicles operating in an underground mine. This tool provides confidence that uninterrupted operation with BEVs is possible. The tool can be used in determining where to locate charging points, how powerful they should be, and how far the vehicle can be driven before it needs to be recharged. Rough energy consumption estimations can also be made by utilising the energy consumption tables provided in this paper.

As was shown in Section 4, many battery driven electric vehicles require only a minimum amount of charging to perform work cycles, but they will require charging, nonetheless. As long as the operator pays attention to the remaining range display of the vehicle and charges the vehicle when needed, there should be no problem with carrying out regular work with battery driven logistics, charging and concrete spraying vehicles. By analysing energy consumption, the right vehicle for the job with the correct battery size and appropriate charging system can be implemented to perform the work that is needed. This way, battery electric underground vehicles can be implemented, and benefits such as operational expense savings, no emissions, and a better working environment, can be obtained.

\section{References}

Battery University 2017, Is Li-Ion the Solution for the Electric Vehicle?, Cadex Electronics Inc., Richmond, viewed 27 March 2017, http://batteryuniversity.com/learn/archive/is_li_ion_the_solution_for_the_electric_vehicle

Global Mining Standards and Guidelines Group (GMSG) 2017, Electric Mine Project, Mining Standards and Guideline Committee, Montreal, viewed 27 March 2017, http://www.globalminingstandards.org/working_group/electric-mine-project/

Halmeaho, T 2016, Electric bus R\&D platform - results from commercial electric buses, presented at the Electric Commercial Vehicles Final Seminar, 11-12 May 2016, VTT Technical Research Centre of Finland Ltd, Espoo, viewed 27 March 2017, https://ecv-fi-bin.directo.fi/@Bin/04dbd0d559d85e0c82a49714553b7eae/1490597983/application/pdf/214622/33_16_NE BI2_Session8_Halmeaho_VTT.pdf

Jacobs, W, Hodkiewicz, MR \& Bräunl, T 2014, 'A cost-benefit analysis of electric loaders to reduce diesel emissions in underground hard rock mines', IEEE Transactions on Industry Applications, vol. 51, no. 3, pp. 2565-2573.

Kukkonen, S 2014, Current Trends in Battery Technology, presented at the Electric Commercial Vehicles National Seminar, 11-12 May 2016, Helsinki, VTT Technical Research Centre of Finland Ltd, Espoo, viewed 27 March 2017, 
https://ecv-fi-bin.directo.fi/@Bin/e380a56f412c5ed54036bd802b279de0/1482998167/application/pdf/210144/Kukkonen _Current\%20Trends\%20in\%20Battery\%20Technology.pdf

Landry, A 2016, New Mine Development Considerations, Diesel Versus Electric Operation of Equipment, presented at the 22nd Annual MDEC Conference (MDEC 2016), 4-6 October 2016, Toronto, Mining Diesel Emissions Council, Kanata, viewed 23 June 2017, http://mdec.ca/2016/S3P1_landry.pdf

Paraszczak, J, Laflamme, M \& Fytas, K 2013, 'Electric load-haul-dump machines: real alternative for diesels?', CIM Journal, vol. 4, no. 1.

Peters, S, de Klerk, N, Reid, A, Fritschi, L, Musk, AW \& Vermeulen, R 2016, 'Estimation of quantitative levels of diesel exhaust exposure and the health impact in the contemporary Australian mining industry', Occupational \& Environmental Medicine, vol. 74, no. 4, pp. 282-289.

Rahkola, P 2016, Electric City Bus Energy Flow Model, presented at the Electric Commercial Vehicles Final Seminar, VTT Technical Research Centre of Finland Ltd, Espoo, viewed 27 March 2017, https://ecv-fi-bin.directo.fi/@Bin/ 81dc024b2770bb1a5c200685c6e5999d/1490598482/application/pdf/213484/07_16_NEBI2_Session2_Rahkola_VTT.pdf

Silverman, DT, Samanic, CM, Lubin, JH, Blair, AE, Stewart, PA, Vermeulen, R \& Attfield, MD 2012, 'The diesel exhaust in miners study: A nested case-control study of lung cancer and diesel exhaust', Journal of the National Cancer Institute, vol. 104, no. 11, pp. 855-868.

The Charging Interface Initiative e.V. 2017, What is the Combined Charging System (CCS)?, CharIN e.V, Berlin, viewed 27 March 2017, http://www.charinev.org/ccs-at-a-glance/what-is-the-ccs/ 